\title{
Bithalamic Infarct Revisited: Clinical, Imaging, Neuropsychological Profile and Prognosis
}

\author{
Thierry Adoukonou ${ }^{1,2, ~ *, ~ M e n d i n a t o u ~ A g b e ́ t o u ~}{ }^{2}$, Raphaël Kaboré ${ }^{1}$, Frédéric Faugeras ${ }^{1}$, \\ Francisco Macian-Montoro $^{1}$, Jean-Michel Vallat ${ }^{1}$, Laurent Magy ${ }^{1}$ \\ ${ }^{1}$ Service de Neurologie CHU Limoges, Limoges, France \\ ${ }^{2}$ Unité d'Enseignement et de Recherche de Neurologie, Faculté de Médecine Université de Parakou, Parakou, Benin
}

Email address:

adoukonouthierry@yahoo.fr (T. Adoukonou)

${ }^{*}$ Corresponding author

\section{To cite this article:}

Thierry Adoukonou, Mendinatou Agbétou, Raphaël Kaboré, Frédéric Faugeras, Francisco Macian-Montoro, Jean-Michel Vallat, Laurent Magy. Bithalamic Infarct Revisited: Clinical, Imaging, Neuropsychological Profile and Prognosis. Clinical Neurology and Neuroscience. Vol. 4, No. 3, 2020, pp. 44-50. doi: 10.11648/j.cnn.20200403.11

Received: June 8, 2020; Accepted: June 19, 2020; Published: July 4, 2020

\begin{abstract}
The bilateral thalamic infarcts are a particular entity by their clinical presentations, neuropsychological, etiologic and prognostic. We report here the presentations of 19 consecutive cases collected at University Teaching Hospital of Limoges. All patients underwent clinical evaluation, neuropsychological (only some of them), a diagnostic imaging and a full workup. A follow-up was performed for certain patients These 19 patients including 11 women, mean age 65.6 years ( $+/-14.0$ years), 13 were hypertensive. Clinically $84.2 \%$ had oculomotor disorders and $73.7 \%$ of vigilance disorders. Seven patients had motor problems that have persisted for two days in one. In territorial terms, 17 had bilateral paramedian infarction including 10 with a stem associated injury; 1 patient had a heart attack in the paramedian and tubero-thalamic territory and the last patient had tubero-thalamic and thalamo-geniculated infarction. On the etiological among the stroke patients bithalamique paramedian, 9 patients had a disease of the small arteries and March 1 cardioembolic infarction. Neuropsychological disorders in patients examined were marked by disorder of episodic memory, working, executive dysfunction, speech disorders. After a mean follow up of 35 months and among all patients with bilateral thalamic stroke 5 patients had died. Our series confirms some data in the literature on the evolution of these heart attacks and suggests that they are mainly topography paramedian, due to small artery disease and have a particular neuropsychological outcome.
\end{abstract}

Keywords: Bithalamic, Stroke, Neuropsychology

\section{Introduction}

The first anatomo-clinical descriptions of thalamic infarcts have been made for more than a century [1]. The interest in their description lies in the particularity of the arterial vascularization of the thalamus [2] with a polymorphism of their different vascular syndromes [3]. Although unilateral thalamic infarctions are common, bilateral thalamic attacks are rare. Pure thalamic infarction accounts for approximately $1.9 \%$ of cerebral infarctions [4]. Bilateral infarction accounts for only $0.6 \%$ [5]. Several clinical pictures have been reported in relation to bilateral thalamic infarction [6-8]. Compared to unilateral thalamic infarction, bilateral thalamic infarction has a worse prognosis because of the neuropsychological disorders and cognitive sequelae that they generate $[7,9,10-13]$. Their diagnosis, previously based on anatomo-clinical data, is made easier with the use of CT-scan and especially cerebral magnetic resonance imaging (MRI).

We report a consecutive series of 19 patients with documented bilateral thalamic infarction.

We aimed to describe the different clinical presentations, the radiological aspects, the neuropsychological profile and the prognosis of these infarcts.

\section{Methods}

\subsection{Type of Study}

This is a retrospective descriptive study of consecutive 
cases of documented bithalamic cerebral infarction at imaging.

\subsection{Patients}

From the admission register of the neurology department of the University Hospital of Limoges from January 1st, 2002 to July 31st, 2009, we selected all the patients hospitalized for a cerebrovascular accident. All patients with recent and simultaneous thalamic bilateral infarction documented with cerebral imaging (CT or MRI) are included in this study regardless of clinical presentation and outcome.

\subsection{Evaluation}

A clinical evaluation was performed in all patients at admission with a detail of the neurological examination on the disorders of the vigilance, oculomotors, sensitive, a detailed neuropsychological evaluation was carried out in the patients able to benefit from it by a neuropsychologist and evaluated disorders of working memory, episodic memory, language, executive functions and other cognitive functions.

Cerebral MRI was performed in all patients with no contraindications. It was performed by using a Siemens 1.5 Tesla machine and included diffusion (DWI), FLAIR, T1 and T2 sequences and T2* gradient echo sequence. A TOF (Time-of-flight) sequence was performed at the same time for a study of the Willis polygon. In parenchymal sequencies, thin sections $5 \mathrm{~mm}$ thick were made. In the presence of a contraindication to MRI, a CT scan was performed to confirm the diagnosis.

The etiological assessment included:

a) Electrocardiogram (EKG).

b) Doppler ultrasound of supra-aortic arteries.

c) A biological assessment: glycaemia, electrolyte count, urea creatinine, blood count, hemostasis assessment.

Depending on the case, the etiological assessment was completed by a cardiac echocardiography (transthoracic or trans esophageal), a continuous ECG recording of $24 \mathrm{~h}$ and an angio-MRI of the supra-aortic trunks with injection of contrast medium or a cerebral arteriography.

\subsection{Data Collection}

Clinical data collected included age, sex, symptoms, neurological deficit as assessed by NIHSS score, Mini Mental State Examination (MMSE). Vascular risk factors were also collected: high blood pressure (antihypertensive medication or blood pressure above $140 / 90 \mathrm{mmHg}$ before hospitalization); diabetes (fasting glucose $>1.26 \mathrm{~g} / 1$ or concept of taking antidiabetic treatment), hypercholesterolemia (total cholesterolemia $>6.5 \mathrm{mmol} / 1$ or taking lipid-lowering agent), smoking, coronary history (myocardial infarction, angina, coronary revascularization) history of stroke or transient ischemic attack; atrial fibrillation).

The etiological classification adopted was TOAST [14].

Imaging was reviewed by a neuroradiologist, blinded to clinical data, to classify infarcts: the location of each side according to the territory concerned (anterior or tuberothalamic, paramedian, infero-lateral or thalamogeniculated, posterior or posterior choroid) according to the classification adopted by Bogousslavsky et al. [7].

Neuropsychological assessment data were collected and classified according to the classical pattern described in the literature [7].

The follow-up data were collected: to become, the RANKIN score modified at the hospital discharge, as well as remotely. For this purpose, all patients, their relatives (parents) or doctor as appropriate were recalled to specify the monitoring data.

\subsection{Data Analysis}

Data was processed and analyzed with SPSS 8.0 software. Given the small size of the sample, a descriptive analysis was performed with the qualitative variables their percentage and for the quantitative variables their mean with standard deviation.

\section{Results}

\subsection{General Data}

From January 1, 2002 to July 31, 2009, 3,027 patients were hospitalized in the ward for an ischemic stroke. Of these cases, nineteen patients had a recent, simultaneous, bithalamic infarction, which was documented by brain imaging. The bithamic infarct represented $0.63 \%$ of all ischemic stroke. There are 11 women and 8 men. They were 32 to 81 years old with an average age of $65.6+/$ 14.0 years. The frequency of risk factors was: $68.5 \%$ for high blood pressure, $15.8 \%$ for diabetes, $15.8 \%$ for smoking, $63.2 \%$ for dyslipidemia $15.8 \%$ for atrial fibrillation and one patient $(5.3 \%)$ had a history of myocardial infarction.

\subsection{Clinical Presentation}

Clinically, oculomotor disorders and vigilance disorders (ranging from drowsiness to coma) were the most common signs. The diagnosis time of infarction ranged from 0 to 120 hours with an average of 27.4 hours +/35.4. Seven patients had motor hemiparesis disorders, which decreased in 6 of them in a few hours and in two days for one). The frequency of clinical signs is summarized in Table 1.

\subsection{Topography}

Topographically 17 patients had bilateral paramedian infarction, 10 of which had an associated mesencephalic lesion; 1 patient had an infarct in the paramedian and tuberothalamic territory and the last patient had a tuberothalamic and thalamogeniculate infarction. The figures 1,2 and 3 showed some example of this data. 


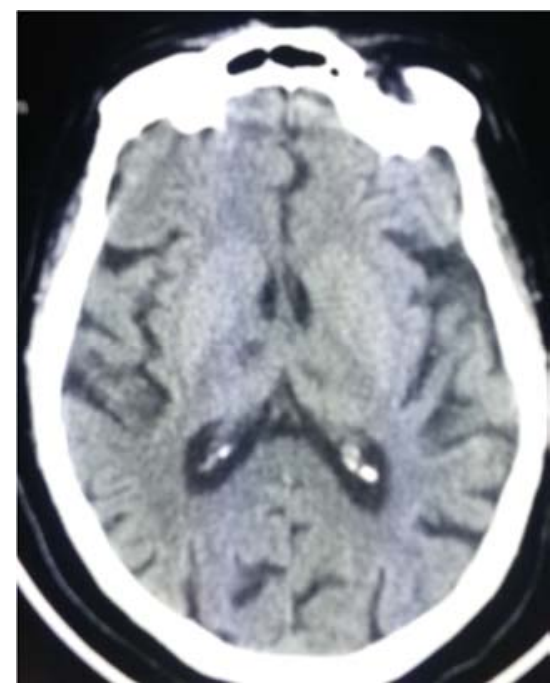

Figure 1. Cerebral CT-scan of patient with tubero-thalamic and parmedian infarction.

Cerebral CT without injection showing right tuberothalamic hypodensity and left paramedian hypodensity.

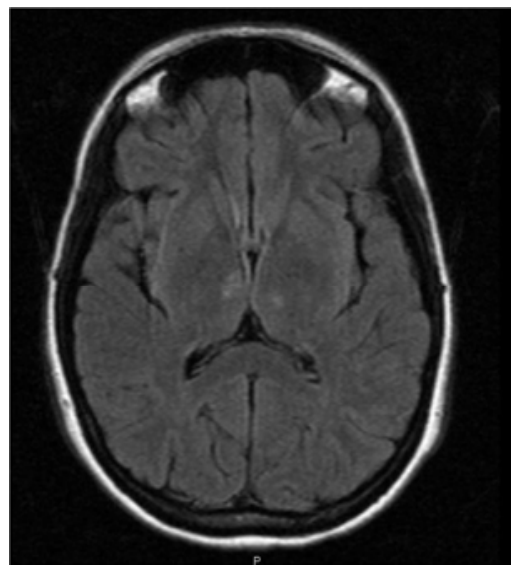

A

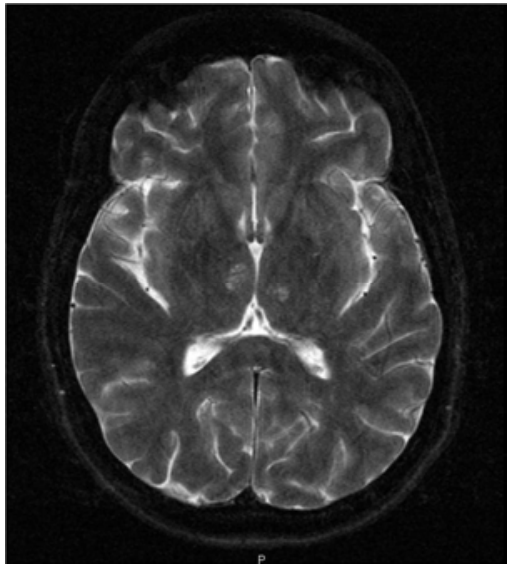

B

Figure 2. Cerebral MRI of the patient with thalamogeniculate and tuberothalamic infarction.

A: FLAIR sequence showing two thalamic hypersignals one in left thalamogeniculé and the other in right tuberothalamic. B: T2 sequence showing the same lesions.

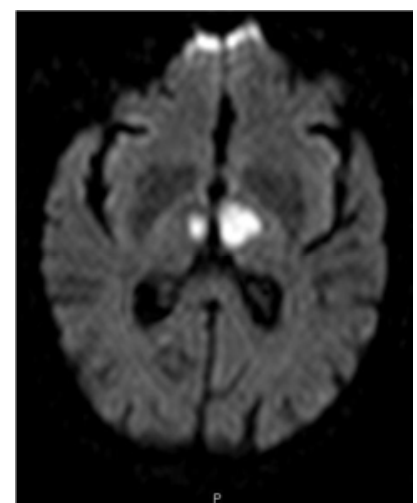

A

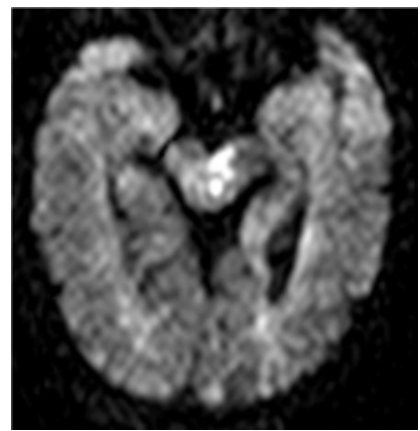

B

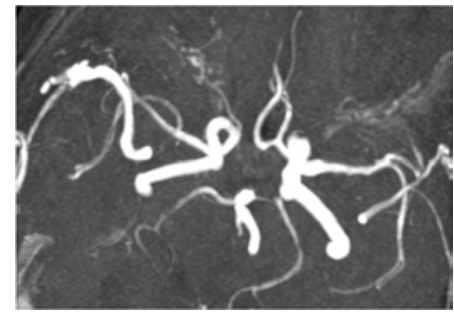

$\mathrm{C}$

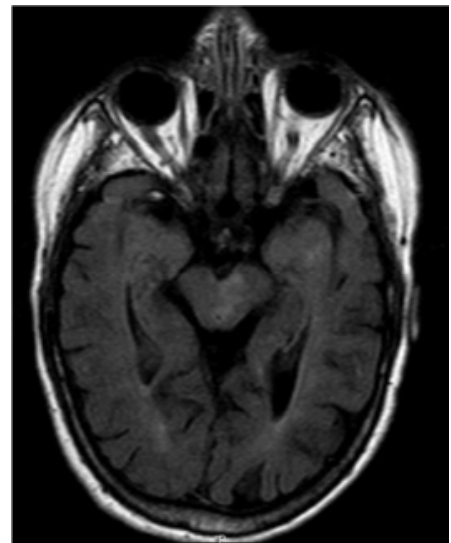

D

Figure 3. Cerebral MRI of Patient 3 with bilateral paramedian infarction associated to mesencephalic infarction.

A: diffusion sequence showing bilateral paramedian bithalamic infarction. B: diffusion sequence showing left mesencephalic infarction.

C: 3 DTOF sequence showing a discrete hypoplasia of the P1 segment of the left posterior cerebral artery.

D: FLAIR sequence showing left mesencephalic lesion. 
Table 1. Frequency of the signs of the 19 patients.

\begin{tabular}{lll}
\hline Signs & Number & Percentage (\%) \\
\hline Oculomotor disorders & 16 & 84.2 \\
Drowsiness & 14 & 73.7 \\
Coma & 14 & 73.7 \\
Hemiparesis & 7 & 36.8 \\
Ataxia & 3 & 15.8 \\
Confusion & 3 & 15.8 \\
Behavioral disorders & 2 & 10.5 \\
Sensory signs & 1 & 5.3 \\
Hallucinations & 1 & 5.3 \\
Risk factors & & \\
Hypertension & 13 & 68.5 \\
Diabetes mellitus & 3 & 15.8 \\
Tobacco use & 3 & 15.8 \\
Dyslipidaemia & 12 & 63.2 \\
Atrial Fibrillation & 3 & 15.8 \\
History of Myocardial infarction & 1 & 5.3 \\
Etiologies & & \\
\hline
\end{tabular}

\begin{tabular}{lll}
\hline Signs & Number & Percentage (\%) \\
\hline Small Vessels disease & 9 & 47.4 \\
Cardioembolic & 3 & 15.8 \\
Atherosclerosis & 2 & 10.5 \\
Other causes & 1 & 5.3 \\
Unknown & 4 & 21.0 \\
\hline
\end{tabular}

\subsection{Etiologies}

According to the classification adopted, they are dominated by the disease of small arteries: 9 (47.4\%), 3 patients had a cardioembolic origin $(15.8 \%)$ and 2 atherosclerosis $(10.5 \%)$. In 4 patients the etiology was indeterminate $(21.1 \%)$. Another (5.3\%) had another cause of cerebral infarction.

The clinical and etiological characteristics of patients with bilateral paramedian infarction are summarized in Table 2 and the presentations of each patient in Table 3.

Table 2. Pattern of the 17 patients with bilateral paramedian infarction

\begin{tabular}{lll}
\hline & NUMBER & PERCENTAGE (\%) \\
\hline SEX (male) & 7 & 41.2 \\
Risk factors & 11 & 64.7 \\
Hypertension & 3 & 17.6 \\
Diabetes mellitus & 2 & 11.8 \\
Tobacco & 12 & 70.6 \\
Dyslipidaemia & & \\
CLINICAL SIGNS & 14 & 82.4 \\
Drowsiness & 13 & 76.5 \\
Coma & 14 & 82.4 \\
Oculomotors disorders & 6 & 35.3 \\
Motor weakness & 2 & 11.8 \\
Behavioural disorders & 1 & 5.9 \\
Sensory signs & 2 & 11.8 \\
Ataxia & & \\
AETIOLOGIES & 2 & 11,8 \\
Atherosclerosis & 9 & 52.9 \\
Small vessels Diseases & 3 & 17.6 \\
Cardio-embolic & 1 & 5.9 \\
Other cause & 2 & 11.8 \\
Unknown & & \\
RANKIN ON DISCHARGE & 2 & 11.8 \\
0 & 10 & 58.8 \\
[1-2] & 1 & 5.9 \\
3 & 2 & 11.8 \\
4 & 2 & 11.8 \\
Death & & \\
\hline
\end{tabular}

Table 3. Main characteristics of each patient with paramedian infarction.

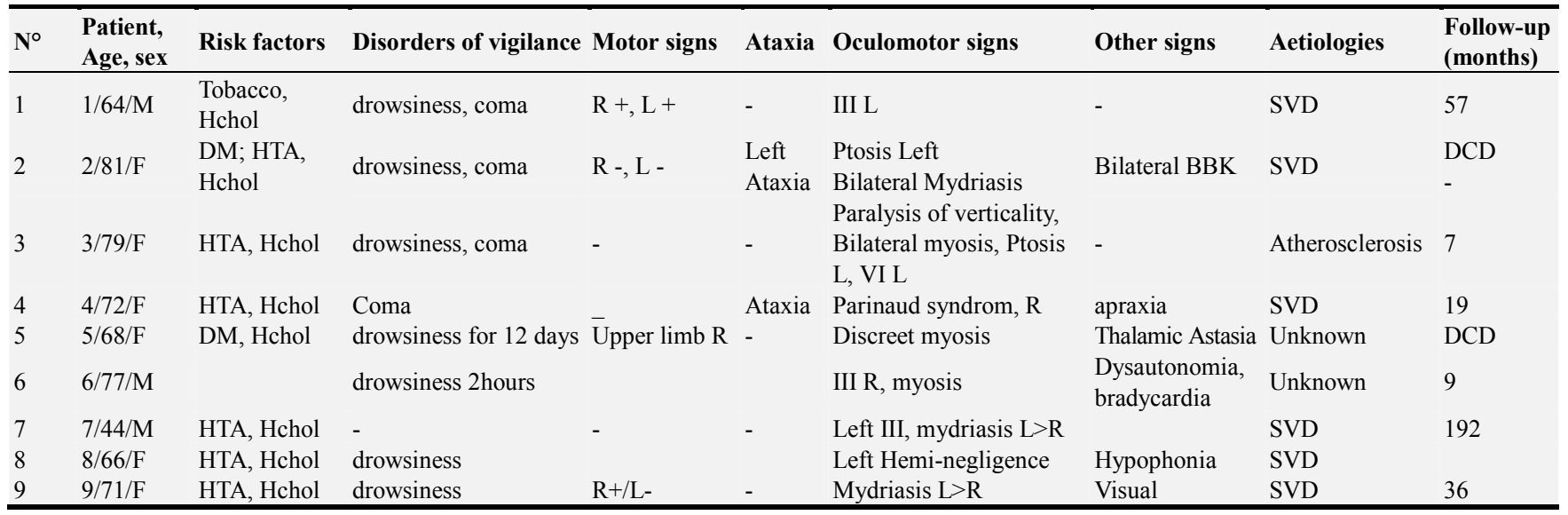




\begin{tabular}{|c|c|c|c|c|c|c|c|c|c|}
\hline $\mathbf{N}^{\circ}$ & $\begin{array}{l}\text { Patient, } \\
\text { Age, sex }\end{array}$ & Risk factors & Disorders of vigilance & Motor signs & Ataxia & Oculomotor signs & Other signs & Aetiologies & $\begin{array}{l}\text { Follow-up } \\
\text { (months) }\end{array}$ \\
\hline 10 & $10 / 52 / \mathrm{M}$ & Tobacco & drowsiness 1 day & & & Bilateral myosis & $\begin{array}{l}\text { hallucinations } \\
\text { Facial paralysis } \\
\text { R }\end{array}$ & SVD & \\
\hline 11 & $11 / 38 / \mathrm{M}$ & Hchol & drowsiness & & & Paralysis of Verticality & & Other & 59 \\
\hline 12 & $12 / 66 / F$ & $\mathrm{AC} / \mathrm{FA}$ & $\begin{array}{l}\text { drowsiness } \\
20 \text { davs }\end{array}$ & $\begin{array}{l}\mathrm{R}+, \mathrm{L}+, \\
\text { Upper limb }\end{array}$ & & $\begin{array}{l}\text { Anisocoria } 0 \\
R>L\end{array}$ & & Cardioembolic & $\begin{array}{l}94 \\
\text { DCD }\end{array}$ \\
\hline 13 & $13 / 73 / \mathrm{F}$ & HTA, Hchol & drowsiness, 72 hours & - & & & - & SVD & 6 \\
\hline 14 & $14 / 75 / \mathrm{M}$ & HTA Angina & & R-, L+ & & Bilateral mydriasis & BBK R & $\begin{array}{l}\text { Cardioembolic, } \\
\mathrm{AF}\end{array}$ & 22, DCD \\
\hline 15 & $15 / 79 / \mathrm{F}$ & HTA AC/FA & drowsiness & & & & & Cardioembolic & \\
\hline 16 & $16 / 76 / \mathrm{F}$ & HTA & Coma & R-, L+ & & Anisocoria $\mathrm{R}>\mathrm{L}$ & & Atherosclerosis & 2, DCD \\
\hline 17 & $17 / 77 / \mathrm{F}$ & HTA, Hchol & $\begin{array}{l}\text { drowsiness, coma, } \\
\text { 6hours }\end{array}$ & R-, L+ & - & III R & & SVD & 30 \\
\hline
\end{tabular}

M: Male, F: Female, HTA: Arterial Hypertension,, R=Right, L: left, III: oculomotor nerve, IV: 4Th cranial nerve, BBK Babinski sign, SVD: Small Vessels Disease, AF: atrial fibrillation, DCD: Dead, HChol: hypercholesterolemia DCD=deceased, DM: diabetes mellitus.

\subsection{Special Cases}

The patient with a left paramedian infarction associated with a right tuberothalamic infarction was a 49-year-old man, hospitalized hypertensive for rapid onset of vigilance disorder with mydriasis of the left eye. The evolution is marked by a rapid worsening of the picture with increased alertness disorders and a decerebration reaction requiring intubation and artificial ventilation followed by a tracheotomy. The evolution was marked by a progressive awakening and a quadriparetic patient with a disappearance of mydriasis and appearance of a ptosis of the right eye. This patient had a normal cerebral perfusion scintigraphy. The patient became bedridden and died 57 months later. To note the presence on the brain scanner of this patient of the associated protuberant and peduncular lesions.

The patient with lesions in the right thalamo-geniculated and left tubero-thalamic territories was 32 years old, with the only history of 10-pack smoking. She was hospitalized for a diplopia of the left eye with a significant decrease in painless visual acuity. She presented on examination vertical diplopia, an attack of the left common oculomotor nerve with disorders of the convergence without intrinsic attack. Explorations for inflammatory pathology (lumbar puncture, visual evoked potentials, cerebral MRI) were negative. MRI brain confirmed the diagnosis of bithalamic infarction with associated mesencephalic involvement. Etiological investigations (transesophageal echocardiography, holterECG, Ultrasound imaging of the vessels of the neck, thrombophilia assessment and cerebral arteriography) were non-contributory. The evolution was marked by a complete recovery in 3 weeks. After 30 months of follow-up, the patient presented no recurrence and no sequelae.

\subsection{Neuropsychological Profile}

Five patients with paramedian bithalamic stroke had a detailed neuropsychological assessment. These are patients 4 , $7,8,9,17$.

The patient 4 had a 9/30 MMSE, episodic, autobiographical, work-related memory disorders, significant executive dysfunction, and visuospatial disorders. She also had an important lack of word as well as reflexive, visuoconstructive and ideomotor apraxia. She was also depressed.

The patient 7 had an alteration of subcortical episodic memory, a decrease in verbal fluency with a lack of the word, and was somewhat psychomotor retarded.

Patient 8 had a MMSE at 20/30, some episodic memory disorders with anterograde amnesia, verbal aspontaneity as well as perseveration phenomena.

The patient 9 had episodic memory disturbances with discrete disturbances of working memory, verbal and visual memory. There was also an executive dysfunction with perseverations, a reduction of verbal fluency, a lack of words with semantic paraphasia. She was easily irritable.

The patient 17 had an overall impairment of memory including episodic memory, working memory. There was also temporo-spatial disorientation, athymhormy, indifference and verbal aspontaneity, joviality sometimes alternating with apathy. The executive dysfunction was very marked. The language was disturbed with semantic paraphasies unrelated to the images. It presented significant visuospatial disorders with constructive apraxia. The data in this report are summarized in Table 4.

Table 4. Neuropsychological pattern of five patients who underwent neuropsycological examination.

\begin{tabular}{lllllll}
\hline Patients & Memory & Executive function & Visuo-spatial disorders & Language & Praxia & Psychologic disorders \\
\hline 8 & EM++ & ++ & - & $+/-$ & - & - \\
4 & EM/WM/AM++ & +++ & ++ & + & C/IM+ & - \\
9 & EM/WM+ & + & - & + & - & Irritable \\
7 & EM++ & + & - & $+/-$ & - & Slowed \\
17 & Globale, WM++ & +++ & +++ & + & $\mathrm{C}+$ & Apathy, frontal \\
\hline
\end{tabular}

WM: work memory, EM: Episodic Memory, AM: autobiographic memory, C: constructor, IM: ideomotor; + minor disturbance, ++ important disturbance, +++ very important disturbance. 


\subsection{Prognosis and Becoming of Patients}

Complete follow-up was performed in 14 patients with follow-up duration ranging from 2 to 94 months after cerebral infarction. The median follow-up was 33 months. At the time of discharge $66.7 \%$ of the patients were independent $($ RANKIN $<2)$. No recurrence was observed during follow-up.

At the end of the follow-up, 5 patients died after an average follow-up of 35 months.

\section{Discussion}

Our study reports the clinical, radiological and neuropsychological pattern of 19 consecutive patients with bithalamic ischemic stroke. The bilateral paramedian location was the most common with $89.5 \%$ of patients. Etiologically it was mainly small artery disease. However, this study has some limitations inherent to retrospective studies such as lack of data for some patients (especially neuropsychological), non-regular monitoring of all patients. In our series, the most commonly observed clinical signs were oculomotor disorders and vigilance disorders (from drowsiness to coma). This frequency of vigilance disorders was previously reported by many authors in paramedian infarcts $[6,8,15]$. These disorders of alertness were all the more severe as mesencephalic involvement was associated. This alteration of vigilance is related to the alteration of the ascending activating reticular formation and its cortical projections through intra-laminar thalami nuclei [16]. Oculomotor disorders were also common in our patients. According to several authors, these disorders could be explained by an impairment of the supranuclear pathways of oculomotricity and / or at the level of the posterior longitudinal strip or even by mesencephalic involvement [3].

Vascular most $(89.5 \%)$ of myocardial infarctions were in the bilateral paramedian territory. This frequency is well above the 50\% reported by Kumral et al. [5] in their series of 16 patients. The paramedian character of the bithalamic infarction is the consequence of the vascularization of the thalamus. Infarctions in the bilateral paramedian territory can be explained by the occlusion of the paramedian arteries of the thalamus (from the P1 segment of the posterior cerebral artery) when these two arteries are born from a single pedicle, which is the case in a third of subjects Sometimes, in the absence of a tubero-thalamic artery arising from the posterior communicating artery, the territory supported by this artery becomes vascularized by the paramedian artery of the thalamus, whose occlusion then generates ischemia and greater clinical signs. Etiologically, small artery disease was most commonly found in our series with more than half of all patients. This frequency is below $62.5 \%(10 / 16)$ of small artery disease reported by Kumral et al. [5]. This high frequency is reported by most authors $[5,17]$. However, in their series of 12 patients with combined thalamic infarction (polar and paramedian) with 3 cases of paramedian, Perren et al. [18] report only one case of small artery disease.
On the neuropsychological level only five patients had benefited from a detailed assessment. This is inherent in the retrospective collection of data and the lack of a protocol dedicated to the study of these patients. However some relevant information can be learned. All patients tested had memory problems and more frequently episodic memory and / or working memory. The memory disorders so frequently reported in the literature are related to involvement of the mamillo-thalamic tract (Vicq d'Azyr beam) $[3,5,8]$ as well as nuclei of the anterior thalamus (involved in the Papez circuit). especially when the tubero-thalamic territory is affected causing long-term memory problems [19] but also anterograde and retrograde memory disorders as well as confabulations $[20,21]$. Cases of Korsakoff syndrome have been reported with thalamic and even bithalamic infarcts [22]. In the case of paramedic infarction, these memory disorders seem to be related to a disconnection of the tonsils and dorso-median nuclei of the thalami. The five patients tested had executive dysfunction. This has been reported by some authors [23-25]. And according to Van der Werf et al. [20] an impairment of at least two nuclei seems necessary to observe executive dysfunction. This could account for the frequency of a dysexecutive syndrome in all patients tested in our series who all have a bithalamic infarction. In addition anatomical studies have shown connections between certain thalamic nuclei and the prefrontal cortex explaining an executive dysfunction in bilateral thalamic lesions [26], which would be related to a fall in blood flow in the prefrontal cortex [27]. It would have been more interesting to test all the patients but the retrospective character of the study did not allow us to affirm the constancy of the memory disorders and the dysexecutive syndrome constituting the classic thalamic dementia.

\section{Conclusion}

Bithalamic infarctions are mainly of paramedian topography and are mainly manifested by disturbances of alertness (all the more so because there is an associated peduncular localization), as well as oculomotor disorders. Small artery disease is the main etiology in our series. Neuropsychologically, memory and executive function disorders are the disorders found consistently in all patients tested. These data are comparable to data in the literature and suggest that the prognosis of bithalamic infarction is mainly neuropsychological.

\section{Conflict of Interest}

All authors declared no conflict of interest regarding this manuscript.

\section{References}

[1] Dejerine J, Roussy G. Le syndrome thalamique. Rev neurol 1906; 14: 521-32. 
[2] Percheron G. Les artères du thalamus humain. Les artères choroïdiennes. Etude macroscopique des variations individuelles et systématisation. Rev Neurol (Paris) 1976; 132: 309-24.

[3] Schmahmann JD. Vascular syndromes of the thalamus. Stroke. 2003; 34 (9): 2264-78.

[4] Carrera E, Michel P, Bogousslavsky J. Anteromedian, central, and posterolateral infarcts of the thalamus: three variant types. Stroke. 2004; 35 (12): 2826-31.

[5] Kumral E, Evyapan D, Balkir K, Kutluhan S. Bilateral thalamic infarction. Clinical, etiological and MRI correlates. Acta Neurol Scand. 2001; 103 (1): 35-42.

[6] Monet P, Garcia PY, Saliou G, Spagnolo S, Desblache J, Franc J, Vallée JN, Deramond H, Lehmann P. Bithalamic infarct: is there an evocative aspect? Radioclinical study. Rev Neurol (Paris). 2009; 165 (2): 178-84.

[7] Bogousslavsky J, Regli F, Uske A. Thalamic infarcts: clinical syndromes, etiology and prognosis. Neurology 1988; 38: 83748.

[8] Bogousslavsky J, Regli F, Delaloye B, Delaloye-Bischof A, Assal G, Uske A. Loss of psychic self-activation with bithalamic infarction. Neurobehavioural, CT, MRI and SPECT correlates. Acta Neurol Scand. 1991; 83 (5): 309-16.

[9] Gentilini M, De Renzi E, Crizi G. Bilateral parmedian thalamic artery infarcts: report of eight cases. J Neurol Neurosurg Psychiatry 1987; 50: 900-9.

[10] van Domburg PH, ten Donkelaar HJ, Notermans SL. Akinetic mutism with bithalamic infarction. Neurophysiological correlates. J Neurol Sci. 1996; 139 (1): 58-65.

[11] Carrera E, Bogousslavsky. The thalamus and behavior. Neurology 2006; 66: 1817-23.

[12] Koutsouraki E, Xiromerisiou G, Costa V, Baloyannis S. Acute bilateral thalamic infarction as a cause of acute dementia and hypophonia after occlusion of the artery of Percheron. J Neurol Sci. 2009; 283 (1-2): 175-7.

[13] Engelborghs S, Marien P, Pickut BA, Verstraeten S, De Deyn PP. Loss of psychic self-activation after paramedian bithalamic infarction. Stroke 2000; 31 (7): 1762-5.

[14] Adams HP Jr, Bendixen BH, Kappelle IJ et al. Classification of subtypes of stroke of acute ischemic stroke: definitions for use in a multicenter clinical trial. Stroke 1993; 23: 35-41.
[15] Castaigne P, Lhermitte F, Buge A, Escourolle R, Hauw JJ, Lyon-Caen O. Paramedian thalamic and midbrain infarct: clinical and pathological study. Ann Neurol 1981; 10: 127-48.

[16] Petit H, Rousseaux M, Clarisse J, Delafosse A. Oculocephalomotor disorders and thalamo-subthalamic infarction. Rev Neurol 1981; 137: 709-22.

[17] Ocariz MNS, Nader JA, Santos JA, Bautista M. Thalamic vascular lesions. Risk factors and clinical course and infarcts and hemorrhages. Stroke 1996; 27: 1530-6.

[18] Perren F, Clarke S, Bogousslavsky J. The syndrome of combined polar and paramedian thalamic infarction. Arch Neurol. 2005; 62: 1212-1216.

[19] Aggleton JP, Saunders RC. The relationships between temporal lobe and diencephalic structures implicated in anterograde amnesia. Memory 1997; 5: 49-71.

[20] Van der Werf YD, Witter PM, Uyslings HBM, Jolles J. Neuropsychology of infarctions in the thalamus: a review. Neuropsychologia 2000; 38: 613-27.

[21] Bogousslavsky J, Regli F, Assal G. The syndrome of unilateral tuberothalamic artery territory infarction. Stroke 1986; 17: 434-441.

[22] Cole M, Winkelman MD, Morris JC, Simon JE, Boyd TA. Thalamic amnesia: Korsakoff syndrome due to left thalamic infarction. J Neurol Sci 1992; 110: 62-7.

[23] Ghika-Schmid F, Bogousslavsky J. The acute behavioral syndrome of anterior thalamic infarction: a prospective study of 12 cases. Ann Neurol 2000; 48: 220-227.

[24] Sandson TA, Daffner KR, Carvalho PA, Mesulam MM. Frontal lobe dysfunction following infarction of the left-sided medial thalamus. Arch Neurol 1991; 48: 1300-3.

[25] Daum I, Ackermann H. Frontal-type memory impairment associated with thalamic damage. Int J Neurosci 1994; 77: 187-198.

[26] Williams PL, WarwickR, Dyson M, Bannister LH (eds) Grays Anatomy. Thirty seventh ed. Churchill Livingstone, Edinburgh, London, Melbourne and New York 1989; 9991004.

[27] Levasseur M, Baron JC, Sette G, Legault-Demare F, Pappata S, Mauguiere F, Benoit N, Tran SD, Degos SD, Laplane D, Mazoyer B. Brain energy metabolism in bilateral paramedian thalamic infarcts. A positron emission tomography study. Brain 1992; 115: 795-807. 